ZOOLOGIA 27 (6): 892-896, December, 2010

doi: $10.1590 /$ S1984-46702010000600009

\title{
Correction of the weight and length for juveniles Atherinella brasiliensis (Actinopterygii: Atherinopsidae) after fixation in formalin and preservation in ethanol
}

\author{
Marcelo T. Melo"; Cíntia Saturnino; Joaquim N. S. Santos; Ruan M. Vasconcellos; \\ Antonio G. Cruz-Filho' \& Francisco G. Araújo', 2
}

\author{
${ }^{1}$ Laboratório de Ecologia de Peixes, Universidade Federal Rural do Rio de Janeiro. Antiga Rodovia Rio-São Paulo, km 47, \\ 23851-970 Seropédica, RJ, Brazil. \\ ${ }^{2}$ Corresponding author. E-mail: gerson@ufrrj.br
}

\begin{abstract}
The present study compared losses of weight and length in specimens of Atherinella brasiliensis (Quoy \& Gaimard, 1825) after fixation in formalin $10 \%$ during ten days, and posterior preservation in ethanol $70 \%$ for 45 days, in two solvents: freshwater and marine water. Additionally, correction factors were proposed to calculate the correction for weight and length from preserved specimens. The specimens were weighted and measured after collection (fresh), and with 10,20,27, 34, 41 and 55 days of fixation plus preservation. The largest losses in weight occurred during the first 20 days ( $10.35 \pm 0.31 \%$ - freshwater; $11.29 \pm 0.44 \%$ - marine water), continuing with lesser intensity up to the $27^{\text {th }}$ day in freshwater dilution, and up to the $34^{\text {th }}$ day in marine water dilution. Weight losses stabilized by the $34^{\text {th }}$ day for both freshwater $(11.77 \pm 0.33 \%)$ and marine water $(13.62 \pm 0.41 \%)$. The largest losses in the total length for the two methods were also observed in the first 20 days ( $7.42 \pm 0.27 \%$ - freshwater; $9.76 \pm 0.26$ - marine water), stabilizing after the $27^{\text {th }}$ day in freshwater $(8.60 \pm 0.26 \%)$ and $20^{\text {th }}$ day in marine water $(9.76 \pm 0.26 \%)$. The losses of weight and total length were significantly dependent on fish size, with smaller individuals suffering the most significant losses. Complete regression equations were proposed for the retro-calculation of fresh weight and total length from the preserved specimens for freshwater $\left(\mathrm{W}_{\text {fresh }}=1.0536 \mathrm{~W}_{\mathrm{p}}+0.0416 ; \mathrm{TL}_{\text {fresh }}=0.9588 \mathrm{TL}_{\mathrm{p}}+5.8437\right)$ and marine water $\left(\mathrm{W}_{\text {fresh }}=1.0868 \mathrm{~W}_{\mathrm{p}}+\right.$ $\left.0.0451 ; \mathrm{TL}_{\text {fresh }}=0.8621 \mathrm{TL}_{\mathrm{p}}+10.425\right)$.
\end{abstract}

KEY WORDS. Back-calculation; initial length; shrinkage; size conversion.

Fixation of fish specimens in formalin $10 \%$ and posterior preservation in ethanol $70 \%$ is a widely used process in ichthyological sampling, due to the usually high number of specimens collected, and the time required to transport and analyze them. Despite its usefulness in keeping specimens preserved for future analysis, this method can alter the weight and length of the subjects (Armstrong \& Stewart 1997, Kristoffersen \& Salvanes 1998, Santos et al. 2009).

The duration of preservation, age of the specimen when collected, and the preservation method employed are factors determining alterations in total weight and length. Overall, the most profound alterations are recorded during the first days after fixation, in small juvenile individuals (RADTKE 1989, FeY $1999,2002)$ and in specimens preserved in ethanol in concentration near absolute (HJörleifsson \& KLeIN-MacPhee 1992). Larvae preserved in ethanol $70 \%$ to $95 \%$ can lose from 5\% to $40 \%$ of their total length (Fowler \& SMith 1983, RadtKe 1989, Jennings 1991). According to TUCKER \& CHESTER (1984), larval shortening is a function of the osmolarity of the liquid used for preserva- tion. For example, formaldehyde diluted in marine water can lead to more significant shortening when compared with freshwater. According to Morkert \& Bergstedt (1990), larval length is frequently shortened by about $10 \%$ after fixation in formalin. This value tends to vary as a function of concentration, salinity and species.

It is common practice to estimate important population parameters such as size structure, growth rate, condition factor and length/weight relationship from preserved specimens. Variables obtained from the latter can be misleading (PORTER et al. 2001, SANTOs et al. 2005). In attempting to correct variations in weight and length that result from preservation techniques, several studies have suggested a correction factor to estimate the initial weight and total length of specimens using appropriate equations (BuchHeister \& Wilson 2005, Fey \& Hare 2005, SANTOS et al. 2009). However, the calculations of weight and total length losses proposed in the literature are generally limited to the effects of either fixation (in formalin) or preservation (in ethanol). Such studies do not consider the combined 
effects fixation followed by preservation techniques, which usually follow one another in the preparation of biological samples. The present study aims to quantify and compare the loss in weight and length in specimens of Atherinella brasiliensis (Quoy \& Gaimard, 1825) fixed in formalin 10\% and posteriorly transferred to ethanol $70 \%$ in two dilution means: freshwater and marine water. Additionally, we propose correction factors for retro-calculation of these measurements from preserved specimens.

\section{MATERIAL AND METHODS}

Information on weight and total length of $A$. brasiliensis juveniles was obtained from 312 specimens collected in the mangrove of the Biological and Archeological Reserve of Guaratiba $\left(23^{\circ} 01^{\prime}-23^{\circ} 03^{\prime} \mathrm{S}, 4^{\circ} 34^{\prime}-44^{\circ} 37^{\prime} \mathrm{W}\right)$, state of Rio de Janeiro (southeastern Brazil). Specimens were collected in fall, 2009 with beach seines (12 x $2.5 \mathrm{~m}$; mesh size $8 \mathrm{~mm}$ between opposite knots). Immediately after collection, specimens were conditioned in plastic bags immersed in ice boxes and transferred to the laboratory, where each individual was weighed with a precision of $0.0001 \mathrm{~g}$ and measured with a precision of $0.01 \mathrm{~mm}$ (fresh measurement). In all treatments each specimen was wrapped in towel paper to dry the body surface before measurements.

After being measured, fresh specimens were separated in two groups of similar size structure, and allocated to different water solutions (freshwater versus marine water). One group was fixed in formalin $10 \%$ (formaldehyde $38 \%$, PA, diluted in freshwater), buffered with Borax $4 \%$ and $\mathrm{pH}$ 7.6. The other group was fixed in formalin $10 \%$ (formaldehyde $38 \%$, PA, diluted in marine water) buffered with Borax $4 \%$ and $\mathrm{pH}$ 7.4. After 10 days in the fixation solution, both groups were transferred to ethanol $70 \%$ (ethanol $99.3^{\circ}$ diluted in freshwater or in marine water).

Individuals were weighed and measured again 10, 20, $27,34,41$ and 55 days after the first measurements. The weight and total length losses were determined for comparisons between fresh specimens and preserved specimens, according to the following equation: Percentage of losses (shrinkage\%) = ((fresh-preserved)/fresh) x 100). Repeated measures ANOVA and TUKEY HSD test $(p<0.05)$ were used to analyze the significance of percent losses in weight and total length between day intervals over 55 days of preservation, and the t-test $(\mathrm{p}<0.05)$ was used to compare the two dilution methods. For each preservation method a linear regression was used to describe the relationship between the two measurements (fresh and preserved) for the weight and the total length and a t-test $(\mathrm{p}<0.05)$ was used to ascertain significant differences between the linear coefficient (y-intercept) from 0 , and the angular coefficient (slope) from 1. It was used to determine the use of simple correction factor ( $y$-intercept $\neq 0$; slope $=1$ ) or the complete correction factor $(y$-intercept $\neq 0$, slope $\neq 1$ ) to estimate the initial weight and the total length of specimens.

\section{RESULTS}

The mean initial total length of $A$. brasiliensis juveniles was similar for the two groups submitted to the two different methods of preservation (t-test $=0.20, \mathrm{p}=0.84$ ), indicating that they had been randomly selected, therefore allowing posterior comparisons. The results of the two methods of preservation (freshwater versus marine water) differed significantly after 55 days, for both weight and total length ( $\mathrm{t}$-test $=4.24, \mathrm{p}$ $<0.001)$.

\section{Dilution in freshwater}

Significant differences were found in losses in weight and total length among the preservation times according to repeated measures ANOVA.

The most pronounced weight losses occurred during the first 20 days ( $10.35 \pm 0.305 \%)$. There were no significant weight losses between 27 and 55 days (Tukey HSD, p > 0.05), after specimens had lost $12.35 \pm 0.48 \%$ of their weight (Fig. 1). Weight remained stable after 27 days.

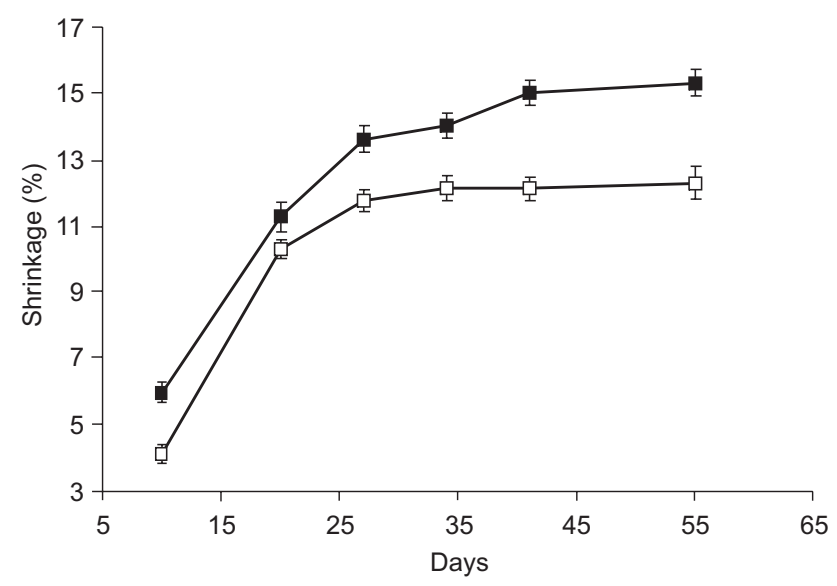

Figure 1. Shrinkage percentage in weight for $A$. brasiliensis juveniles in different dilutions: marine water $(\square)$ and freshwater $(\square)$.

The most pronounced decreases in total length were also observed in the first 20 days $(7.42 \pm 0.19 \%)$. No significant decreases in total length were observed after 27 days, an indication that length remained stable thereafter (Tukey HSD, p > 0.05); the mean loss after 55 days was $9.45 \pm 0.29 \%$ (Fig. 2).

\section{Dilution in marine water}

The most pronounced reduction in weight occurred during the first 20 days $(11.29 \pm 0.44 \%)$. After 27 days no significant losses were observed in weight, indicating weight stabilization (Tukey HSD, p > 0.05) with cumulative mean losses in weight after 55 days being $14.91 \pm 0.42 \%$ (Fig. 1).

The most pronounced decrease in total length was also observed in the first 20 days $(9.76 \pm 0.26 \%)$. No significant 
losses in total length were observed after 20 days, indicating total length stabilizations (Tukey HSD, $\mathrm{p}>0.05$ ). Mean losses in total length after 55 days were $10.61 \pm 0.43 \%$ (Fig. 2).

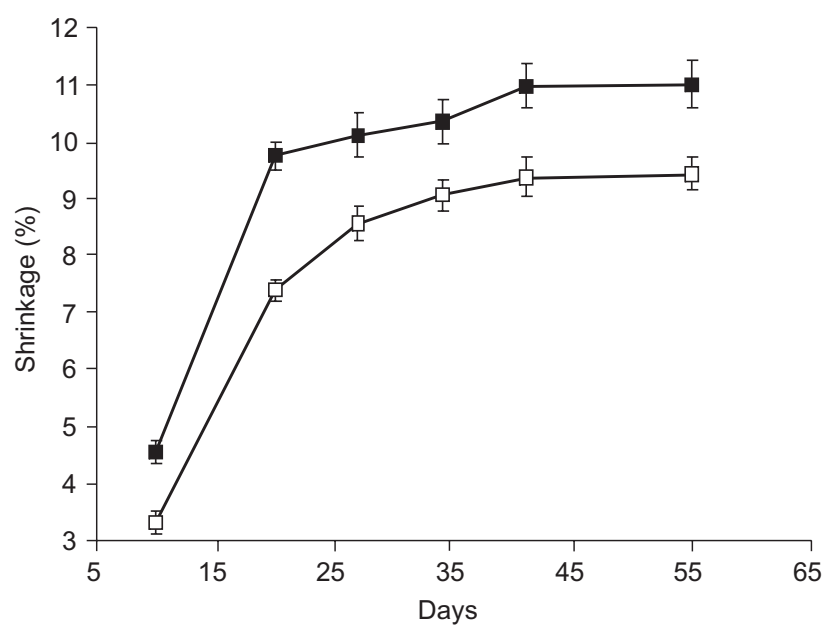

Figure 2. Shrinkage percentage in total length for $A$. brasiliensis juveniles in different dilutions: marine water $(\boldsymbol{\square})$ and freshwater $(\square)$.

Losses in weight and length varied according to the total length of specimens: smaller specimens had the most significant losses in the two preservation methods (t-test, $\mathrm{H}_{0}$ : slope $=$ $0, p<0.05)$. The test of slope-homogeneity indicated that the fastest losses in length occurred in specimens diluted in marine water (Tukey HSD, p > 0.0001), while the losses in weight did not differ between the two preservation methods (Figs 3 and 4).

All linear coefficients (y-intercepts) resulting from regressions between fresh weight versus preserved weight, and fresh total length versus preserved total length were significantly different from zero $\left(\mathrm{H}_{\mathrm{o}}\right.$ : $\mathrm{y}$-intercept $=0$; t-test, $\left.\mathrm{p}<0.001\right)$ in the two methods investigated (Figs 5 and 6).

Slopes (b) resulting from regression of fresh weight versus preserved weight and of fresh total length versus preserved total length for 55 days were significantly different from $1\left(\mathrm{H}_{\mathrm{o}}\right.$ : slope $=1$; t-test, $\mathrm{p}<0.05$ ); therefore the correction of weight and length should be performed by using the complete correction factor (Tab. I).

\section{DISCUSSION}

In our results, weight and total length losses in preserved specimens were associated with the preservation method. More precisely, the treatment using marine water accounted for the largest percentage losses overall. According to TUCKER \& CHESTER (1984), alterations in body dimensions generally depend on the osmolarity of the preservative. Consequently, specimens kept in formaldehyde or ethanol diluted in marine water tend to undergo more marked alterations (loss in weight and length) when compared with specimens kept in formaldehyde or ethanol diluted in freshwater. Morkert \& BERGSTEDT (1990) recorded that lamprey larvae fixed in formalin $10 \%$ shrink according to formalin concentration and salinity. Our findings corroborate these results.

Ethanol has the capacity to extract water and lipids from tissues, resulting in weight losses (STEEDMAN 1976). Another factor that can account for differences in how much specimens decrease in length is the rigidity of specimens preserved in ethanol when compared with those fixed in formalin (KRISTOFFERSEN \& SALVANES 1998), which makes measurements more difficult and leads to errors. Overall losses in specimens preserved in ethanol in the present study may be caused by losses per si, originated by organic losses, and also by comparatively higher rigidity of specimens after preservation.

Losses in weight and length by both methods have changed with time of preservation. According to Fey \& Hare (2005) the length of juveniles of Brevoortia tyrannus (Latrobe, 1802) preserved in ethanol $95 \%$ stabilized within a few days. By contrast, the length of Cololabis saira (Brevoort, 1856) larvae preserved in formalin 5\% stabilized after one month (Oоzекі et al. 1991). For several fish species, the length stabilized within a few days to one month (Fey 1999, SMITH \& Walker 2003, Мокu et al. 2004). Our findings indicate that juveniles of $A$. brasiliensis loose most weight and length up to 20 days into preservation.

The losses in total length recorded for $A$. brasiliensis were more pronounced in smaller specimens. This finding corroborates results obtained for other species (HJÖRLEIFSSON \& KLEINMacPhee 1992, Fey 2002, Fey \& Hare 2005) such as Pseudopleuronectes americanus (Walbaum, 1792), Clupea harengus Linnaeus, 1758, Osmerus eperlanus (Linnaeus, 1758), and $B$. tyrannus. According to Fey (1999), alterations in larvae, post-

Table I. Correction equations to estimate the weight and total length for juvenile $A$. brasiliensis.

\begin{tabular}{llcccrrrr}
\hline $\begin{array}{c}\text { Preservation } \\
\text { method }\end{array}$ & Regression equation & $\mathrm{n}$ & $\mathrm{R} \mathrm{R}^{2}$ & $\begin{array}{c}\text { Total length } \\
\text { and weight }\end{array}$ & $\begin{array}{c}\mathrm{t} \text {-test } \\
\text { Slope }=1\end{array}$ & $\mathrm{p}$ & $\begin{array}{c}\mathrm{t} \text {-test } \\
\text {-intercept }=0\end{array}$ & $\mathrm{p}$ \\
\hline Freshwater & TLfresh $=0.9588 \mathrm{TLP}+5.8437$ & 156 & 0.98 & $26.72-64.44 \mathrm{~mm}$ & 3.63 & $<0.05$ & 7.52 & $<0.0001$ \\
& Wfresh $=1.0536 \mathrm{WP}+0.0416$ & & 0.99 & $0.13-2.22 \mathrm{~g}$ & 6.65 & $<0.05$ & 5.28 & $<0.0001$ \\
\multirow{3}{*}{ Marine water } & TLfresh $=0.8621 \mathrm{TLP}+10.425$ & 156 & 0.96 & $27.01-63.89 \mathrm{~mm}$ & 8.56 & $<0.05$ & 11.88 & $<0.0001$ \\
& Wfresh $=1.0868 \mathrm{WP}+0.0451$ & & 0.98 & $0.14-2.12 \mathrm{~g}$ & 7.64 & $<0.05$ & 4.70 & $<0.0001$ \\
\hline
\end{tabular}

ZOOLOGIA 27 (6): 892-896, December, 2010 


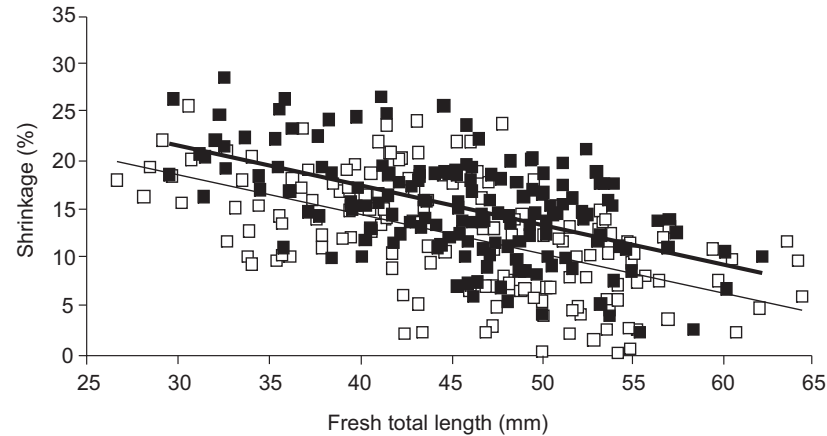

Figure 3. Shrinkage percentage in weight in relation to total length for $A$. brasiliensis: freshwater $(\square)\left(y=-0.40 x+30.84, R^{2}=0.31\right)$, marine water $(\boldsymbol{\square})\left(\mathrm{y}=-0.41 \mathrm{x}+33.98, \mathrm{R}^{2}=0.29\right)$.

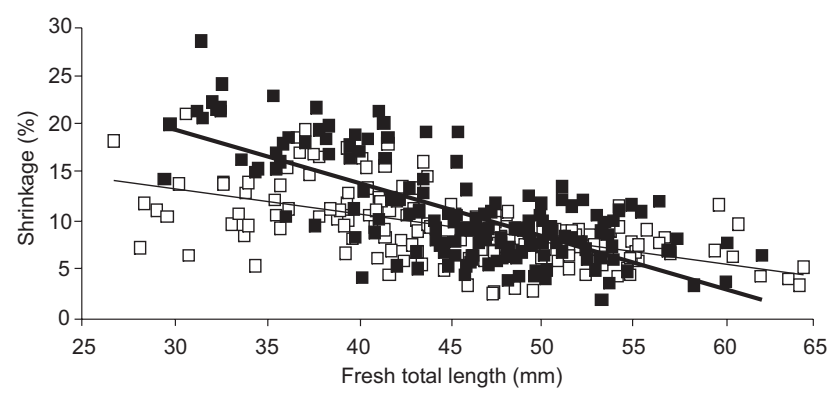

Figure 4. Shrinkage percentage for total length in relation to total length for $A$. brasiliensis: freshwater $(\square)\left(y=-0.25 x+21.06, R^{2}=\right.$ $0.33)$, marine water $(\square)\left(y=-0.55 x+36.19, R^{2}=0.51\right)$.

larvae and juveniles are a serious problem in ecological and biological studies of fish species, which can lead to errors in growth ratio estimation. Because preservation is inevitably associated with losses in weight and length correction factors are necessary to estimate initial weight and length using appropriate equations (BUCHHEISTER \& WILSON 2005).

The weight and length of preserved $A$. brasiliensis can be converted to fresh weight and length by conversion equations. Conversion factors using complete equations are necessary to correct the weight and length of specimens in the present study. Our finding are corroborated by SANTOS et al. (2009) who proposed correction factor using complete equations for Sardinella janeiro (Eigenmann, 1894).

\section{ACKNOWLEDGMENTS}

This work was financially supported by Conselho Nacional de Desenvolvimento Científico e Tecnológico (CNPq proc. 522317/96-0) and Fundação Carlos Chagas Filho de Amparo à Pesquisa do estado do Rio de Janeiro (FAPERJ proc. E-26/170.258/2001).

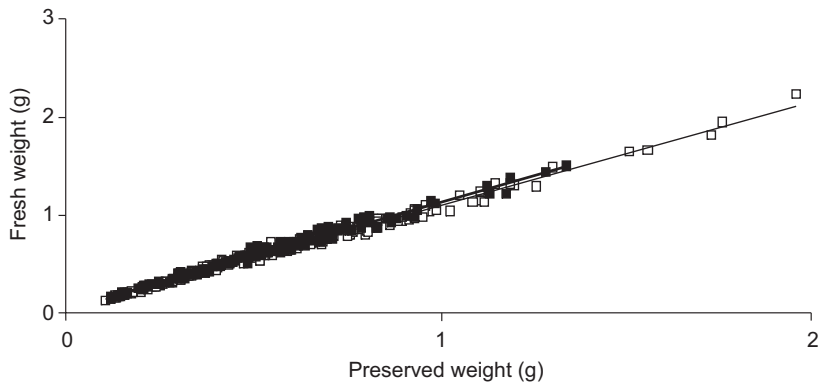

Figure 5. Relationship between fresh weight and preserved weight for $A$. brasiliensis: freshwater $(\square)\left(y=1.0536 x+0.0416, R^{2}=0.99\right)$; marine water $(\boldsymbol{\square})\left(y=1.0868 \mathrm{x}+0.0451, \mathrm{R}^{2}=0.98\right)$.

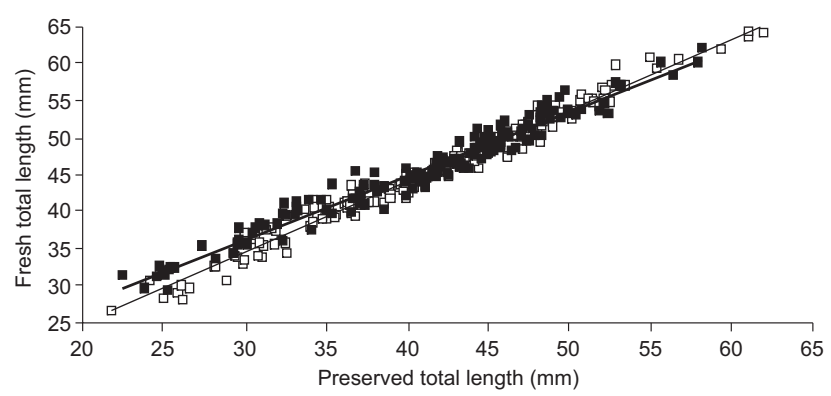

Figure 6. Relationship between fresh total length and preserved total length for $A$. brasiliensis: freshwater $(\square)(y=0.9588 x+5.8437$, $\left.\mathrm{R}^{2}=0.981\right)$; marine water $(\square)\left(\mathrm{y}=0.8621 \mathrm{x}+10.425, \mathrm{R}^{2}=0.96\right)$.

\section{LITERATURE CITED}

Armstrong, J.D. \& D.C. Stewart. 1997. The effects of initial length and body curvature

on shrinkage of juvenile Atlantic salmon during freezing. Journal of Fish Biology 50: 903-905.

BuchHeIster, A. \& M.T. Wilson. 2005. Shrinkage correction and length conversion equations for Theragra chalcogramma, Mallotus villosus and Thaleichthys pacificus. Journal of Fish Biology 67: 541-548.

Fey, D.P. 1999. Effects of preservation technique on the length of larval fish: methods of correcting estimates and their implication for studying growth rates. Archive of Fishery and Marine Research 47: 17-29.

FEY, D.P. 2002. Length correction of larval and early-juvenile herring (Clupea harengus L.) and smelt (Osmerus eperlanus L.) after preservation in formalin and alcohol. Bulletin of the Sea Fisheries Institute 1 (155): 47-51.

Fey, D.P. \& J.A. Hare. 2005. Length correction for larval and early juvenile Atlantic menhaden (Brevoortia tyrannus) after preservation in alcohol. Fishery Bulletin 103: 725-727. 
FowLer, G.M. \& S.J. SMIth. 1983. Length changes in silver hake (Merluccius bilinearis) larvae: effects of formalin, ethanol, and freezing. Canadian Journal of Fisheries and Aquatic Sciences 40: 866-870.

Hü̈rleifsson, E. \& G. Klein-Macphee. 1992. Estimation of live standard length of Winter Flounder Pleuronectes americanus larvae from formalin-preserved, ethanol-preserved and frozen specimens. Marine Ecology Progress Series 82: 1319.

Jennings, S. 1991. The effects of capture, net retention and preservation upon lengths of larval and juvenile bass, Dicentrarchus labrax (L.). Journal of Fish Biology 38: 349-357.

Kristoffersen, J.B. \& A.G.V. SALVANes. 1998. Effects of formaldehyde and ethanol preservation on body and otoliths of Maurolicus muelleri and Benthosema glaciale. Sarsia 83: 95-102.

Moku, M.; K. Mori \& Y. Watanabe. 2004. Shrinkage in the body length of Myctophid fish (Diaphus Slender-Type spp.): Larvae with various preservatives. Copeia 3: 647-651.

Morkert, S.B. \& R.A. Bergstedt. 1990. Shrinkage of sea lamprey larvae preserved in formalin. North American Journal of Fisheries Management 10: 484-486.

Oozeki, Y.; Y. Watanabe; Y. KujI \& S. Takahashi. 1991. Effects of various preservatives on the body length of saury larvae. Bulletin Nature Fisheries Research Institute 53: 15-21.

Porter, S.M.; A.L. Brown \& K.M. Bailey. 2001. Estimating live standard length of net-caught walleye pollock (Theragra chalcogramma) larvae using measurements in addition to standard length. Fishery Bulletin 99: 691-696.

RADTKE, R.L. 1989. Larval fish age, growth, and body shrinkage: information available from otoliths. Canadian Journal of Fisheries and Aquatic Sciences 46: 1884-1894.

Santos, J.N.S.; M.A. Silva; R.M. Vasconcellos \& F.G. Araujo. 2005. Effect of the conservation period of the specimens on the microstructure quality of sagittae otoliths in Anchoa tricolor (Agassiz) (Clupeiformes: Engraulidae). Revista Brasileira de Zoologia 22 (4): 949-952.

Santos, J.N.S.; F.G. AraúJo \& D.S. Silva. 2009. Length correction for early-juvenile Brazilian herring Sardinella janeiro (Eigenmann, 1894) after preservation in formalin, ethanol and freezing. Neotropical Ichthyology 7 (1): 87-92.

Smith, B. B. \& K.F. WALKer. 2003. Shrinkage of $0+$ carp (Cyprinus carpio) after preservation in ethanol. Marine and Freshwater Research 54: 113-116.

Steedman, H.F. 1976. General and applied data on formaldehyde fixation and preservation of marine zooplankton. In: Zooplankton Fixation and Preservation, UNESCO Press, Paris. Monographs on Oceanographic Methodology 4: 103-154.

Tucker, J.W \& A.J. Chester. 1984. Effects of salinity, formalin concentration and buffer on quality of preservation of southern flounder (Paralichthys lethostigma) larvae. Copeia 5: 981-988.

Submitted: 01.XII.2009; Accepted: 27.VIII.2010.

Editorial responsibility: Wolmar B. Wosiacki

ZOOLOGIA 27 (6): 892-896, December, 2010 